\title{
Seismicity Pattern Analysis in and around Shillong Great Earthquake of 1897
}

\author{
Ananta Panthi ${ }^{1}$ and Jyoti Bhattarai ${ }^{2}$ \\ ${ }^{1}$ Department of physics, Butwal Multiple Campus, Butwal \\ ${ }^{2}$ Department of physics, Birendra Multiple Campus, Chitwan
}

\begin{abstract}
The seismicity data of the last 50 years (1963-2012) of the region bounded by $89^{\circ}-93^{\circ} \mathrm{E}$ and $24^{\circ}-28^{\circ} \mathrm{N}$ have been analyzed for understanding the seismic characteristics in and around Shillong great earthquake of 1897. The distribution of earthquakes for this period shows sporadic nature of seismic activity in the region. The study of earthquake frequency, the spatio-temporal patterns of seismicity, the focal depth distribution, and the energy release pattern during the period 1963-2012 considering the events with cut-off magnitude $\left(m_{b} \geq 4.5\right)$ have revealed that the region is seismically active. It is observed that most of the seismicity over the Shillong region is associated with the Main Central Thrust, Main Boundary Thrust and Transverse faults. The earthquake occurrence pattern is non-uniform and mostly shallow and intermediate focus in nature. Further, it has been observed that there exists a non-uniform pattern of seismic energy release.
\end{abstract}

Keywords: seismicity; b-value; faults; focal depth; spatial; temporal.

\section{INTRODUCTION}

The Shillong plateau, forming a northeastern prolongation of the Indian shield, occurs as a pivot to the west of the Naga Hills and to the south of the Eastern Himalayas. The Shillong Plateau has an average elevation of about $1000 \mathrm{~m}$. To the south the Plateau is limited by the $\sim 320 \mathrm{~km}$ long E-W Dauki fault system and to the west by the Jamuna and Dhubri faults. The Dauki fault separates the Precambrian basement of the Shillong Plateau to the north and the thick Tertiary sediments of the Bengal basin to the south. The Shillong plateau is known as detached area from Indian shield comprises the Archaean to Proterozoic gneisses and is covered by quartzite, grit and slates [1]. This plateau also consists of patchy remnants of a Tertiary cover and some unclassified crystalline rocks. The topography of Shillong plateau shows a criss- cross pattern of faults cutting the ancient rocks of the basement [2]. Bilham and England [3] suggested 'pop-up tectonics' for the Shillong Plateau, which is bounded by two reverse faults, the north dipping Dauki fault to the south and WNW-ESE trending south dipping deep seated 'Oldham fault' at the boundary of the Plateau and the Brahmaputra valley. The Shillong plateau has experienced vertical uplift [4] and the upliftment is believed to be $\sim 1 \mathrm{~km}$ [3]. The Shillong plateau is mostly $\mathrm{E}-\mathrm{W}$ trending hill. This region consists of several faults with three main directions of orientation i.e. NW-SE, NE-SW and N-S. The major faults are mapped in the Shillong Plateau region such as Dauki fault trending E-W to the south [2], Chedrang fault and Oldhan fault to the north, Kopili fault to the east and Dhubri and Tista fault to the west.

Shillong Plateau region is seismically active in Northeast India, where a great earthquake (1897) has occurred in the past. The region has been seismically very active from 1897 to 1930 during which one great earthquake (1897) and three large earthquakes with $7 \leq M \leq 7.6$ (1918, 1923 and 1930) have rocked the region in just 33 years period. Seismicity in this zone is considered as the plateboundary zone activity. In the Shillong plateau, the focal depth is mostly within $60 \mathrm{~km}$.

\section{DATA ANALYSIS}

Seismicity data were compiled using almost all the available earthquake catalogues such as International Seismological Centre (ISC), National Earthquake Information Centre (NEIC- USGS), 
Advanced National Seismic Systems (ANSS), National Oceanic Atmospheric Administration (NOAA) as sources of earthquakes. Using the earthquakes records from the above catalogues, a database has been compiled using a rectangular search method for the period from 1963-2012. The database was finalized by removing repeated events. The frequency of earthquakes with magnitude and depth of Shillong Plateau is depicted in Table 1.

Table 1: Frequency of earthquakes with respect to magnitude and focal depth in Shillong Plateau of Northeast India from 1963 to 2012.

\begin{tabular}{|c|c|c|c|c|c|c|c|c|c|}
\hline \multicolumn{9}{|c|}{ Number of earthquakes } & \multirow{3}{*}{$\begin{array}{c}\text { Annual } \\
\text { frequency }\end{array}$} \\
\hline \multirow{2}{*}{\multicolumn{4}{|c|}{$\begin{array}{l}\text { Magnitude }\left(\mathrm{m}_{\mathrm{b}}\right) \\
\text { All magnitude }\end{array}$}} & \multicolumn{5}{|c|}{ Focal depth (km) } & \\
\hline & & & & \multicolumn{2}{|c|}{$\mathrm{m}_{\mathrm{b}} \geq 4.5$} & & & & \\
\hline$\leq 4.4$ & $\geq 4.5$ & $\geq 5.0$ & $\geq 6.0$ & $\leq 40$ & $40-70$ & $>70$ & Shallow & $\begin{array}{l}\text { Inter- } \\
\text { mediate }\end{array}$ & $\mathrm{m}_{\mathrm{b}} \geq 4.5$ \\
\hline 317 & 187 & 58 & 1 & 331 & 142 & 31 & 181 & 6 & 4 \\
\hline
\end{tabular}

The b-value has been calculated by using GutenbergRichter [5] formula for the earthquakes occurred in Shillong and its adjoining region from 1963-2012. The relationship established here for the region is as $\log \mathrm{N}=9.51-1.56 \mathrm{M}$, with $\mathrm{R}^{2}=0.97$. The best fit equation provides cutoff magnitude as $\mathrm{m}_{\mathrm{b}} 4.5$ and b-value as 1.56 . The b-value computed here 1.56 is greater than 1 (universal value) [6]. It indicates that the stress accumulated in the region is very high.

(a)

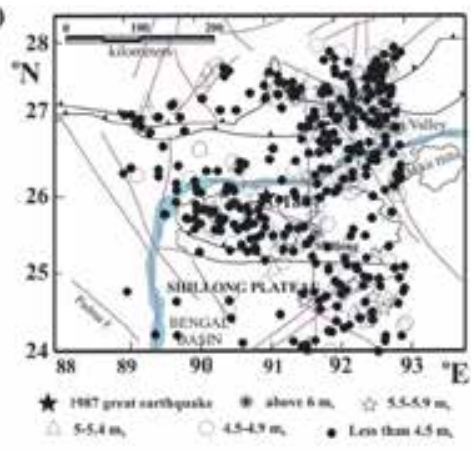

(b)

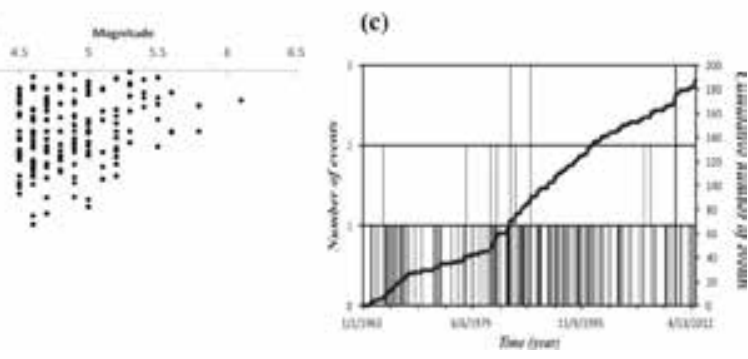

Fig. 1: (a) Spatial distribution of earthquakes with respect to magnitude, (b) Focal depth distribution of earthquakes with magnitude and (c) Temporal patterns of earthquake in Shillong Plateau and its adjoining region for the period1963 to 2012 .

The spatial distribution of all earthquakes in Shillong and its adjoining region for period 19632012 is shown Fig. 1(a). The compiled seismicity data indicate that Shillong plateau region has been mildly active during 1963-2012. Three major seismically active centers can be seen from the spatial distribution of earthquakes as shown in Fig. 1 (a). The larger magnitude earthquakes (M 5.5-5.9) during this period are concentrated to the southeast portion of the plateau near Dauki fault whereas smaller events (M 4.3-5.4) are distributed almost uniformly throughout the plateau. Dauki fault,Dapshi thrust, Kopili fault and Sylhet fault are responsible for earthquake generation in this region. During the period 1963-2012, the total number of events occurred in the region is 504 that includes $26 \%$ events with $\mathrm{m}_{\mathrm{b}} 4.5-4.9$ and $12 \%$ with $\mathrm{m}_{\mathrm{b}} \geq 5.0(5.0-6.1)$.

Focal depth distribution with magnitude is depicted in Fig. 1(b). The focal depth distribution of this region 
is that $94 \%$ events are shallow focus earthquakes. It is also observed that about $70 \%$ of larger magnitude earthquakes $\left(m_{b} \geq 5.0\right)$ have occurred between the focal depths ranges $30-55 \mathrm{~km}$. Temporal pattern (Fig. 1c) shows extremely low seismic activity up to 1981 followed by a sudden jump in 1982 . The seismic activity increases from 1982. The seismic activity is very high in 2009 .

\section{RESULT AND DISCUSSIONS}

The seismic activity of a region depends upon the geologic setup and arrangement of tectonic features. The seismic data set, for the period 1963-2012, has been critically analyzed for b-values, the spatiotemporal patterns of seismic activity, the focal depth distribution of events in Shillong Plateau and its adjoining region. The $b$ - value thus estimated help understanding earthquake occurrence pattern and its relation with other tectonic regions. The spatiotemporal distribution of earthquakes in relation with geological structures helps for understanding the future seismic hazards and its assessment. The seismic activity in Shillong plateau is confined in three seismically active segments trending northeastsouthwest and southeast. Temporal pattern shows that the region is due for a great earthquake. The focal depth distribution of earthquakes in the region shows shallow focus in nature. The major features of northeast India Himalaya and its adjoining regions is the result of collision tectonics of India and Eurasia. This part of Himalaya is under high compression due to northward movement of Indian plate which is eventually subducting beneath the Eurasian plate. It is believed that northward movement of Indian plate beneath Eurasian plate could be one of the most promising reasons for intense seismic activity in this region.

\section{REFERENCES}

[1] Nandy, D. R., Geodynamics of Northeastern India and the adjoining region, $\mathrm{ABC}$ Publications, Calcutta, pp. 209, 2001.

[2] Evans, P., The tectonic framework of Assam, Jour. Geol. Soc. Ind., 5, 80- 96, 1964.

[3] Bilham, R., and England, P., Plateau 'pop up' in the great 1897 Assam earthquake, Nature, 410, 806-809, 2001.

[4] Deshikachar, S. V., A review of the tectonic and geological history of Eastern India in terms of "plate tectonics" theory, Jour. of Geol. Soc. India; 15, 137-49, 1974.

[5] Gutenberg, B., and Richter, C. F., Frequency of earthquakes in California, Bull. Seismo. Soc. Am., 34, 185-188, 1944.

[6] Richter, C .F., Elementary Seismology, Euracia publishing house Pvt.Ltd. New Delhi, 1969. 